\title{
Impacts of the new high speed rail services on small tourist cities: the case of Toledo (Spain)
}

\author{
B. Guirao \& F. Soler \\ Department of Transportation, Technical University of Madrid, Spain
}

\begin{abstract}
Toledo is a medium size town of 78.000 inhabitants, located in central Spain, 70 $\mathrm{km}$ south of Madrid, and constitutes the capital of the province of Toledo and of the autonomous community of Castille-La Mancha. It was declared a World Heritage Site by UNESCO in 1986 for its extensive cultural and monumental heritage as one of the former capitals of the Spanish Empire and place of coexistence of Christian, Jewish and Moorish cultures. This paper presents and analyses the results of a study on the impact of the new high-speed rail on Toledo local and interurban mobility. The location of the station, at the edge of the city, conditions the urban mobility of the users (tourists and commuters to Madrid) and demands a good integration of the various modes of transportation. The research includes a survey of train users, with more than 5000 valid questionnaires collected during the week between 22nd and 28th October 2007.
\end{abstract}

Keywords: high speed rail line, interurban mobility, mobility survey, transportation planning.

\section{Introduction}

Up to now, the main target of new high-speed lines has been connecting two big population areas which size justifies the public investment required for its construction. But also, small and medium size cities are generally included in interior points of these lines. After more than fifteen years of experience, Spanish high-speed network is centered in Madrid and covers more than $1500 \mathrm{~km}$. (see Figure 1), offering not only services of long distance but also shuttles in short relations (less than 200 kilometres) with a high frequency of trains. These later services are being called "regional high-speed services" and the new high speed line Madrid-Toledo (inaugurated on November 2005), with 
the lowest travel time (30 minutes) of these regional services until now, represents an interesting case of study in which tourism is going to play an important and differential role against other short high speed distance relations. The relationship between the two cities Madrid-Toledo includes an important daily road and rail traffic of commuters and tourists

Table 1: $\quad$ High-speed regional services in Spain.

\begin{tabular}{|l|c|c|}
\hline \multicolumn{1}{|c|}{ Relation } & $\begin{array}{c}\text { Travel Time } \\
(\mathrm{min})\end{array}$ & Opening of service \\
\hline Madrid-Ciudad Real & 50 & $18-10-1992$ \\
\hline Madrid-Puertollano & 65 & $18-10-1992$ \\
\hline Córdoba-Sevilla & 45 & $11-12-2004$ \\
\hline Madrid-Toledo & $\mathbf{3 0}$ & $\mathbf{1 5 - 1 1 - 2 0 0 5}$ \\
\hline Córdoba-Málaga & 65 & $20-02-2008$ \\
\hline Madrid-Segovia & 35 & $20-02-2008$ \\
\hline
\end{tabular}

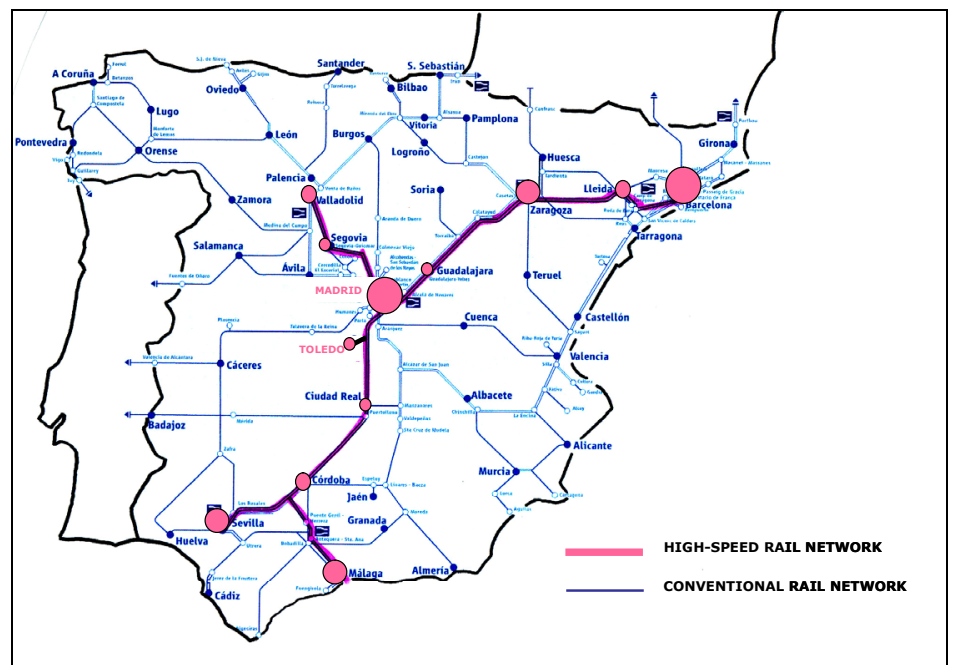

Figure 1: $\quad$ Location of Toledo on the Spanish high-speed rail network.

The Madrid-Seville line, inaugurated in 1992, signified the beginning of the construction of an ambitious high-speed railway network in Spain, which is currently called the "high-performance network" (Red de Altas Prestaciones) in the new Strategic Plan for Infrastructures and Transport (see Ministerio de Fomento [1]). This first line, available for passengers only, has served for several research studies, which have focused mainly on the mobility impact generated by the implementation of this new infrastructure, mainly in long distance relations (see Guirao [2] and Guirao et al. [3]). Surprisingly mobility between some interior points of the line and the end nodes started to show interesting patterns, for example this is the case of Ciudad Real, with 70.000 inhabitants. Its peculiarity inside the national transport system lies on the fact that it was the first 
capital of a province in Spain provided with more than 20 daily high-speed rail shuttles (50 minutes travel time) to Madrid since 1993 . In fact, railway mobility between Madrid and Ciudad Real amounted to 892.744 travellers in 2002 and some authors have already studied the relationship of dependence of these small cities on the big attractor centers, analysing their metropolitan integration in big cities (see Ureña [4], and Mannone [5]). Are these regional services of highspeed operating as "suburban trains"?

Toledo enjoys, as well, a high-speed rail link with Madrid, but its orography is quite opposite to Ciudad Real. Getting to know the urban structure and the planning evolution of a certain town is the first step that needs to be taken in order to understand the way its inhabitants move. The old part of Toledo, with an inestimable historical value, is located on a hill and partially surrounded by the river Tajo, which runs along what used to be an old roman wall. This old center has been surpassed by the gradual growth of the town, which spreads at the bottom of the hill organized into separate neighbourhoods. The old train station, located at the edge of the city, has been restored to cater for the high-speed trains and the old conventional line has been dismantled. Before the beginning of the construction works, in 2002, rail mobility between Madrid and Toledo in 2002, was high and amounted to 874.336 travellers, but this figure got to 1.140 .502 in 2006 (the first operation year of the high speed rail line), with a $30 \%$ increase. Travel time using the old conventional line was 60 minutes and with the new one was reduced to 30 , and alternative road modes (private vehicle and interurban buses) could not compete with the high-speed train, in terms of travel time, particularly during Madrid peak hours. This new type of transport offer, perfectly compatible with the work activity of both cities, has given place to a group of commuters which is also favoured by the existence of monthly tickets which are economically very advantageous compared with the simple tickets. At the same time, during working days, Toledo tourists used to allocate themselves in the high-speed seats not taken by the commuters. We will try to analyse this mobility patters studying the results of the survey in a greater depth.

\section{Operation of the Madrid-Toledo rail line}

Before designing the survey questionnaire, it was necessary to study the mobility data collected by the operating company during the first two years of service. Figures 2 and 3 show the evolution of the occupation rate during a medium week of 2006 (both ways, Madrid-Toledo and Toledo-Madrid). The shape of the two graphics is quite different: while in Figure 2 (Madrid-Toledo) the peak occupation rates are reached between 9:20 a.m. and 15:00 p.m., in Figure 3 (Figure 3 ) the maximum rates are achieved in the early morning hours and at the end of the day. This latter pattern usually represents a typical commuter relation. Taking into account the fact that Toledo is a tourist city and that the majority of the Toledo visitors come from Madrid, the peak occupation rates detected in Figure 2 could reveal the presence of the tourist travellers. These tourist travellers seem to come back from Toledo together with the commuters living in Madrid in the last trains in the evening. 


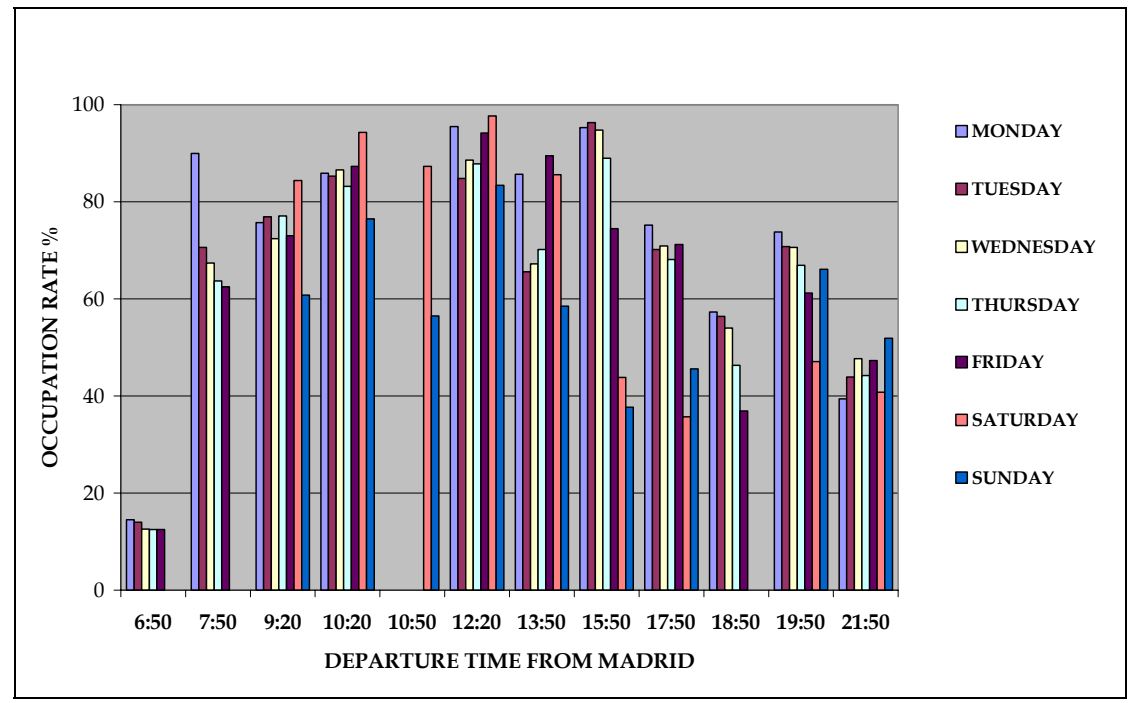

Figure 2: Madrid-Toledo. Evolution of the trains' occupation rate during an average week of 2006 .

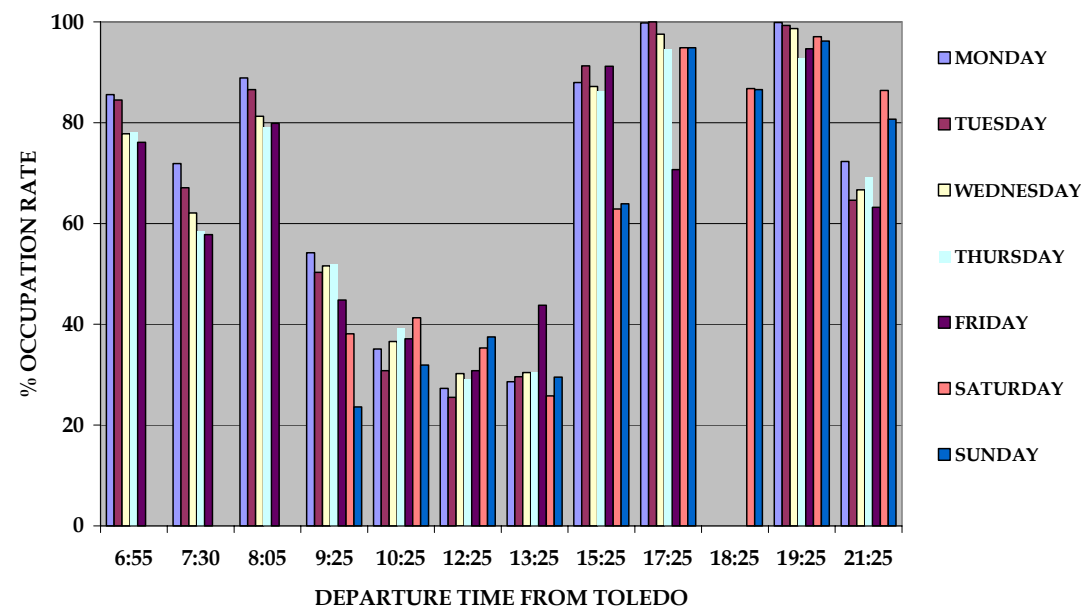

Figure 3: Toledo-Madrid. Evolution of the trains' occupation rate during an average week of 2006 .

Regarding the new mode travel cost, Table 2 shows the types of available tickets in Madrid-Toledo rail relation. We can appreciate that season tickets are economically very advantageous compared with the simple tickets and favour clearly the presence of commuters. 
Table 2: $\quad$ Fares (euros) in Madrid-Toledo rail line.

\begin{tabular}{|l|c|c|c||}
\hline Type of Ticket & $\mathbf{2 0 0 5}$ & $\mathbf{2 0 0 6}$ & $\mathbf{2 0 0 7}$ \\
\hline Single ticket (one way) & 8,0 & 8,3 & 8,6 \\
\hline Go and return ticket (10\% discount) in different days & 14,4 & 14,9 & 15,5 \\
\hline Go and return ticket (20\%discount) the same day & 12,8 & 13,3 & 13,8 \\
\hline Single ticket with air Connection (25\% discount) & 6,0 & 6,2 & 6,5 \\
\hline Season Ticket (10 trips) & 68,1 & 71,0 & 73,5 \\
\hline Season Ticket (20 trips) & 114,0 & 118,0 & 122,0 \\
\hline Season Ticket (30 trips) & 136,0 & 141,0 & 146,0 \\
\hline Season Ticket (40 trips) & 158,0 & 163,0 & 169,0 \\
\hline Season Ticket (50 trips) & 180,0 & 186,0 & 193,0 \\
\hline
\end{tabular}

\section{The survey campaign}

The purpose of the survey campaign was to establish Madrid-Toledo high-speed mobility patterns, not only during working days but also at weekends. The campaign was finally carried out during the week between 22nd and 28th October 2007 (Monday, Wednesday, Friday, Saturday and Sunday) and the questionnaires consisted of three different blocks of questions. The purpose of the first one was to define the shuttle user's profile (socio-economic profile and trip features). The second one was exclusively directed to the "commuters" and its purpose was to know the characteristics and certain stated preferences of these daily users. Finally the third block was also exclusively for tourists (tourism as trip purpose). The pilot survey showed that the percentage of non-Spanish speaker tourists was high, so in order to collect a complete sample of users during aforementioned week it was necessary to translate the questionnaire into English.

The number of forms computerized was 5.321 and this figure included the most representative trains of each of the five surveyed days. In order to detect different mobility patterns the sample taken from the working days trains was studied separately from the weekend sample.

Regarding working days, $50 \%$ of trips have a work purpose, $30 \%$ are tourists and $8 \%$ students. Concerning commuters (users with season tickets), $70 \%$ of them have their residence in Toledo and only 20\% are living in Madrid. These latter figures are unusual, comparing to other regional relations already studied in which the commuter mobility in the two ways of the relation is better balanced. One of the aspects that was analysed in the survey was whether there was a strong commuter dependence on the high-speed train, but in case of Madrid-Toledo relation results show that more than $60 \%$ of the commuter would not change their work or location of residence if the high-speed train changed the timetable or frequency (being not compatible with their work timetable).

Regarding tourist trips on working days, $70 \%$ of these travellers are not Spanish and use to buy their tickets in the origin train station on the same day of 
the trip. It is plain that we are mainly talking about visits to Toledo of less than 12 hours; even the percentage of tourist spending the night in Toledo does not increase at weekends.
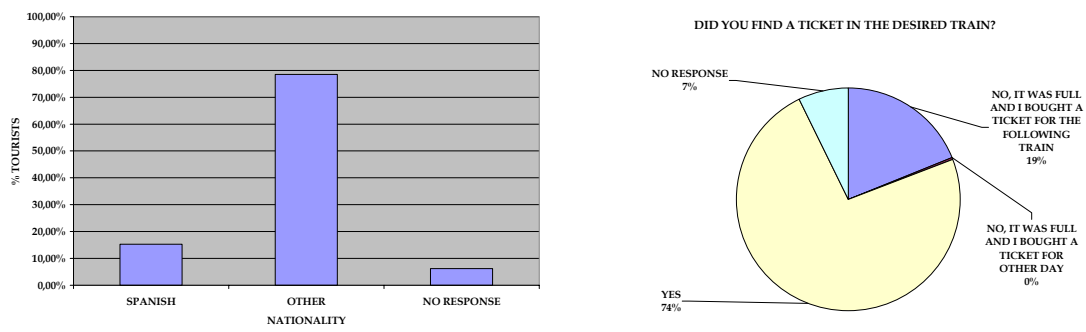

Figure 4: Tourists on a working day. Nationality (left) and availability of ticket for the desired train (right).

The survey also gathered information regarding the time it takes for the users to arrive at the station as well as the transport mode they use for that purpose. While most of the commuters living in Madrid can reach Atocha high-speed train station in less than 25 minutes, to the Toledo residents it takes around 15 minutes to reach the station. Taking into account the fact that most Madrid users live mainly in the city centre $(80 \%)$, the distance from their homes to the aforementioned station allows good communication mainly by the underground and suburban train, and also, but not as importantly as the former, by bus. Therefore, the transportation mode used by Madrid residents in their homeAtocha trips is mainly private car $(31 \%)$, underground $(16 \%)$, bus $(11 \%)$ and suburban train $(21 \%)$. Only $13 \%$ of the travellers walk to the station and the rest of all must arrive by taxi or by car (driven by a different person - kiss and ride). Nevertheless, $69 \%$ of Ciudad Real commuters go to the station by private cars (parking near the station is available free of charge), $8 \%$ use the urban bus because of the existence of a service between downtown and the high-speed train station and $17 \%$ walk to the station.

Regarding the tourists access to Atocha station, the transportation mode used is mainly metro (44\%) and pedestrian access has also an important weight: $20 \%$ of the tourist travellers walk to Atocha station. Nevertheless, when these tourists arrive at Toledo station, the lack of information about the presence of an urban bus line coordinated with the high-speed trains arrivals, cause that more than $50 \%$ of them have to walk to the city historical center.

\section{Analysis of Toledo rail station}

Research on the role of the new high-speed stations is not new. In 2002, a Spanish research paper developed by the Department of Transport of the University of Castilla-La Mancha, (Menéndez et al. [6]) tried to analyze the mobility in European medium and small size towns, just like the type of town Toledo is: located in a high-speed train line, connected with an attracting centre 
in a trip time shorter than 90 minutes and with a connexion frequency of at least 9 daily services (both ways). The timetables should be compatible with work activity in order to facilitate the existence of commuters. As a result of the criteria mentioned above, the chosen cities turned out to be twelve: Mâcon, Le Creusot, Montbard, Vendôme and Valence (France); Göttingen, Würzburg and Fulda (Germany); Arezzo (Italy); Katrineholm (Sweden); and Ciudad Real and Puertollano (Spain). For all of them, the existence of commuters had modified some aspects of local mobility according to the place where the station was situated in relation to the city centre (central station, external station and station located at the edge of the city). Nevertheless, the strategies used by the local authorities for mobility improvement were very different.

Toledo station is clearly located at the edge of city, restoring the old station building which dates from 1919. As at the nineteenth century stations, the location of the station at the edge of the city might be regenerating urban development in the surroundings of the station. Some interesting residential uses, as well as tertiary, and the opening of new axes of development are now being planned after two years of the arrival of the high speed train to the city of Toledo (there is a new POM Plan de Ordenación Municipal- Local Urban Planning-, approved last $26 \mathrm{March}$ ). These areas will be regenerated, as they were part of denigrated city suburbs. Distance to the city center is the main issue in this typology. In case of Toledo, pedestrian itinerary from the station to the city center takes a medium of 20 minutes. Also dimension of the area around the station will determine the scale of the urban development and the possibilities of regenerating a new consolidated area around the city.

In Toledo, the interurban bus station is placed far way the present rail station (15 minutes walking), so this modal transfer is quite difficult and which is more important, there is no signposting that could guide the user to the terminal from the train station. Urban buses company (UNAUTO) offers a new line (line 22) with a stop located outside the grounds of the station and this line has a coordinated timetable that could drop the train users at Toledo historical center in 15 minutes. The problem is there is not information about Toledo public
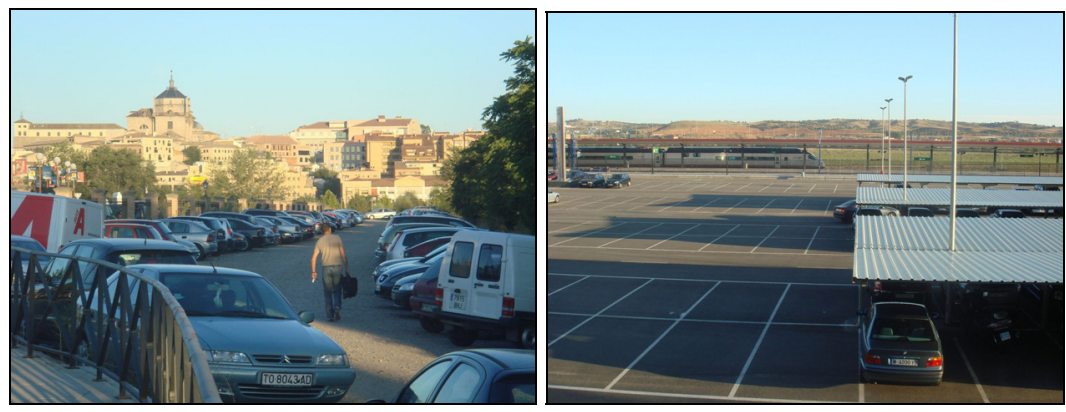

Figure 5: Parking at Toledo Station. The parking area inside the grounds of the station (right) is empty on a working day while the nonsurfaced streets close to the station are full of parked cars during the daytime (left). 
transportation inside the grounds of the rail station. For that reason, as the survey results shows, the majority of the tourists use to walk to the city center, and the commuters living in Toledo use their car to get to the station.

The grounds of the station are provided with a very generous parking area with a total capacity of 336 cars and only the first 15 minutes are free of charge (time enough to pick up a traveller). The parking operation company (COMFERSA) offers special price to frequent users, but the parking area remains empty most of the day because there are some streets (not surfaced) closed to the station (see Figure 5) where user can park free of charge.

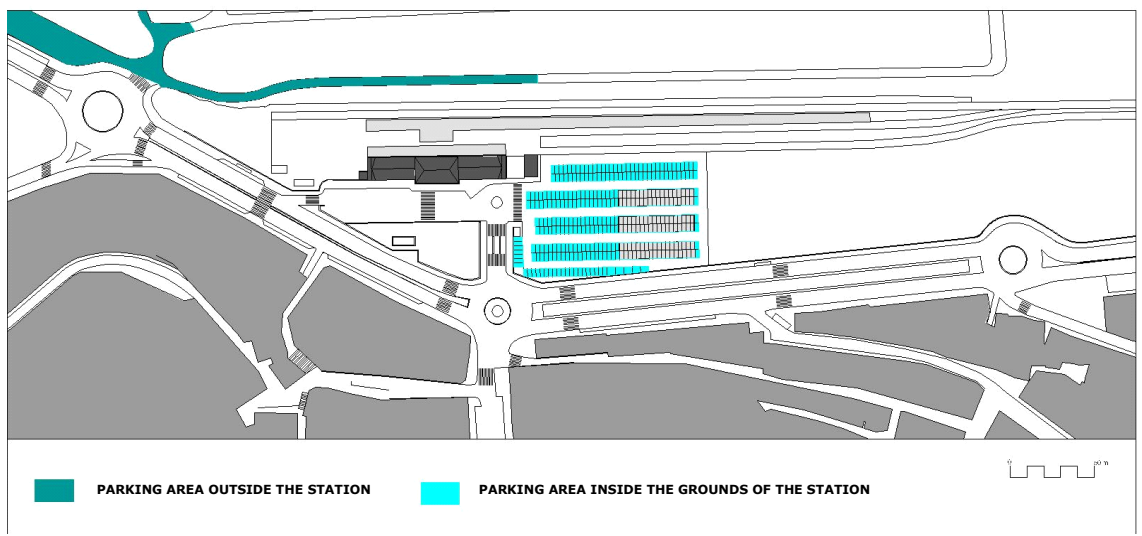

Figure 6: Ground plan of Toledo Station surroundings. Parking options for private vehicle.

\section{Conclusions}

This paper shows the main mobility impacts generated by the new high-speed line Madrid-Toledo. The household survey carried together with the functional analysis of Toledo station made up a key tool for this research. On working days, commuters $(50 \%)$ and tourists $(30 \%)$ are the main users of the trains, but regarding the commuters it has been detected that the level of dependence on the high-speed services is lower than in other similar regional relations. Concerning tourists, nowadays the capacity of the high-speed line can just serve their needs, but in the future if commuters or tourist demand increases, the operation company will be forced to reinforce the offer with more trains. These problems do not appear at weekends.

Regarding Toledo station, information signposting related to urban bus services must be implemented inside the grounds of the station. At the same time, pedestrian access should be improved and private vehicle parking controlled. new opportunity of development is also considered at the surroundings of the new station, the opportunity of developing a new area, according to the new users and the new infrastructure. Public planning strategies 
must be designed in order to organize the future of these areas, for market cannot be the only way to rule this concern.

Lastly, the usefulness of this kind of studies lies on the fact that they show problems that can be solved in other high-speed regional relations, with the help of a good transportation planning. An example for this is the lack of information about the existence of coordination among the urban buses service and highspeed trains. Tourism and commuter transportation needs should be attended.

\section{Acknowledgements}

The conclusions drawn in this article are the consequence of a research project, (completed in November 2007), which was financed by the Ministry of Public Works of Spain-Ministerio de Fomento- and carried out by the Department of Transportation of the Technical University of Madrid. RENFE Operadora (the operation rail company) made significant contributions to its progress, authorising the campaign of surveys carried out on board and placing the trains' staff at the disposition of the research group during these days.

\section{References}

[1] Ministerio de Fomento, Plan Estratégico de Infraestructuras y Transporte 2005-2020 PEIT. Centro de Publicaciones del Ministerio de Fomento, 2005.

[2] Guirao, B., The Madrid-Seville experience, Journal of the Institution of Civil Engineering, vol.159, pp. 109-115, 2006.

[3] Guirao, B.; Menéndez, J.M. and Rivas, A., New Spanish High-speed Rail Lines: An Opportunity to Analyse Induced Traffic. Transports, Vol.419, pp. 98-123, 2002.

[4] Ureña, J.M. el al., Alta velocidad Ferroviaria e Integración metropolitana en España: El caso de Ciudad Real y Puertollano, EURE, XXXI, n 92, pp.87404, 2005

[5] Mannone, V. Gares TGV et nouvelle dynamiques urbaines en centre ville: le cas des villes desservies par le TGV Sud-Est. Les Cahiers Scientifiques $d u$ Transport. 31, pp 71-97, 1997.

[6] Menéndez, J.M, Guirao, B., Coronado, J.M., Rivas, A., Rodríguez, F.J., Ribalaygua, C. and. Ureña, J. M., New High-Speed Rail Lines and Small Cities: Locating the Station, Proceedings of the Conference The Sustainable City_Wessex Institute of Technology, pp. 810-820, 2002. 